\title{
Modification of Ceramic Membranes by Silica Nanoparticles with Thiourea Functions
}

\author{
Veronika V. Tomina (D, Galyna I. Nazarchuk, and Inna V. Melnyk $(\mathbb{D}$ \\ Department of Surface Chemistry of Hybrid Materials, Chuiko Institute of Surface Chemistry NASU, Kyiv 03164, Ukraine \\ Correspondence should be addressed to Veronika V. Tomina; v.v.tomina@gmail.com and Inna V. Melnyk; in.melnyk@gmail.com
}

Received 30 November 2018; Revised 20 March 2019; Accepted 15 April 2019; Published 30 April 2019

Academic Editor: Silvia Licoccia

Copyright (C) 2019 Veronika V. Tomina et al. This is an open access article distributed under the Creative Commons Attribution License, which permits unrestricted use, distribution, and reproduction in any medium, provided the original work is properly cited.

\begin{abstract}
Sol-gel approach based on hydrolytic copolycondensation of tetraethoxysilane (TEOS) with ethylthiocarbamidepropyl triethoxysilane (ETUS) was used to deposit functional layers with thiourea functions on the surface of macroporous ceramic alumina membrane supports. According to SEM images, such layers are composed of nanoparticles of about $60-70 \mathrm{~nm}$ in diameter, while IR spectroscopy data confirmed the presence of functional groups introduced during the synthesis. Such functionalization technique allows combining sorption and membrane technology and could be successfully used to remove trace quantities of copper, cadmium, and silver metal ions from aqueous solutions.
\end{abstract}

\section{Introduction}

Methods of membrane separation used in water purification technology are conventionally divided into dialysis, electrodialysis, microfiltration, ultrafiltration, and reverse osmosis. In the process of ultrafiltration, the macromolecular substances exceeding the membrane pore sizes are retained, while the solvent freely permeates through the membrane. From ordinary filtration, ultrafiltration is distinguished by the smaller size of particles undergoing separation, while the pore size of the membrane should not exceed the size of the particles. In addition, this process results in the concentration of initial solution or suspension, not the precipitate formation as in conventional filtration. The mechanism of ultrafiltration is close to ordinary filtering [1].

Membranes including thiourea groupings on the basis of different supports were synthesized and studied by many scientists due to their selectivity [2-5]. Thiourea derivatives were shown to have a strong complexation with different metals. For this reason, they were used to produce selective electrodes for silver(I) [6] and rubidium(I) [7] ions, mercury(II) membrane sensors [8], microporous cellulose membranes [9], and porous membranes with high selectivity and efficiency for the recovery of trace amounts of aurum(III) $[10,11]$.
Various adsorbents with thiourea groups were synthesized using the sol-gel technique and analyzed in terms of their adsorption properties. Porous materials with thiourea groups in the surface layer are proved to be perspective for the sorption of heavy metal ions from aqueous solutions. Earlier, the scientists from our research team developed a one-step technique for the synthesis of the xerogels [12], the bridged xerogels $[12,13]$, mesoporous MCM-41 [12, $14]$, and SBA-15 $[15,16]$ type materials with thiourea functional groups and showed their ability to remove mercury(II) and silver(I) ions from aqueous solutions [12, 16, 17].

Therefore, in the current research, we considered the possibility to deposit active layers containing thiourea functions $\left[\equiv \mathrm{Si}\left(\mathrm{CH}_{2}\right)_{3} \mathrm{NHC}(\mathrm{S}) \mathrm{NHC}_{2} \mathrm{H}_{5}\right]$ on the surface of planar and tubular ceramic membrane supports.

\section{Materials and Methods}

2.1. Materials. Planar ceramic $\mathrm{Al}_{2} \mathrm{O}_{3}$ membrane supports are purchased from Anodisc, Whatman, with a diameter of $25 \mathrm{~mm}$ and an average pore size of $0.2 \mu \mathrm{m}$. Tubular ceramic $\mathrm{Al}_{2} \mathrm{O}_{3}$ membrane supports are purchased from Khust Ceramic Plant, Ukraine, which are cylindrical tubes with inner and outer diameters of 6 and $12 \mathrm{~mm}$, respectively, and $25 \mathrm{~cm}$ in length. The average pore size is about 


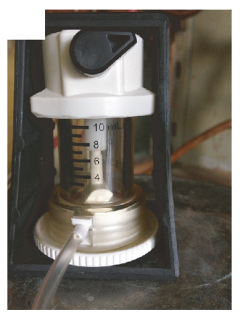

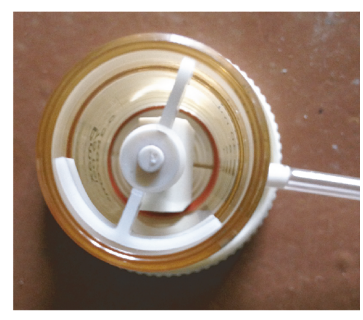

(a)

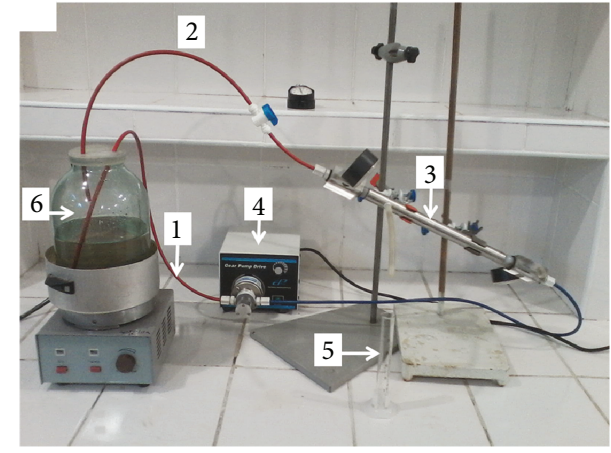

(b)

FIgURE 1: Amicon stirred ultrafiltration cell (Millipore Corporation, USA) (a) and experimental setup for studying transport characteristics of tubular membranes in the circulation mode (b): 1-feed solution, 2-retentate, 3-membrane cell, 4-pump, 5-container with purified permeate, and 6-container with feed solution.

$5 \mu \mathrm{m}$ of the outer layer and $0.3 \mu \mathrm{m}$ of the inner working layer. The following reagents are used for functionalization: tetraethoxysilane, $\mathrm{Si}\left(\mathrm{OC}_{2} \mathrm{H}_{5}\right)_{4}$ (TEOS, Aldrich, 99\%), ethylthiocarbamidepropyl triethoxysilane, $\left(\mathrm{C}_{2} \mathrm{H}_{5} \mathrm{O}\right)_{3} \mathrm{Si}$ $\left(\mathrm{CH}_{2}\right)_{3} \mathrm{NHC}(\mathrm{S}) \mathrm{NHC}_{2} \mathrm{H}_{5}$ (ETUS, synthesized as in $[15,18])$, ethanol $(96 \%)$, and $0.0024 \mathrm{~N} \mathrm{HCl}$.

\subsection{Sol Preparation and Membrane Functionalization} Techniques. To prepare the functionalizing sol, both TEOS and ETUS were subjected to preliminary acidic hydrolysis. For TEOS hydrolysis, it was mixed with an equal volume of ethanol $(1.12 \mathrm{~mL})$ at constant stirring $(500 \mathrm{rpm})$ followed by the addition of $1 \mathrm{~mL}$ of hydrochloric acid $(0.0024 \mathrm{M})$ as a catalyst. The hydrolysis was carried out at $70-80^{\circ} \mathrm{C}$ for $30 \mathrm{~min}$ until the formation of transparent solution. Separately, the hydrolysis of trifunctional silane (ETUS) was carried. Similarly, equal volumes of ETUS and ethanol $(4 \mathrm{~mL}$ each) were mixed in a glass with the addition of $0.9 \mathrm{~mL}$ of hydrochloric acid $(0.0024 \mathrm{M})$ as a catalyst at room temperature $\left(20-25^{\circ} \mathrm{C}\right)$. The mixture was stirred until the formation of transparent sol ( $3 \mathrm{~min})$. The sols of TEOS and ETUS were mixed at TEOS/ETUS molar ratio $3 / 1$ and constant stirring at $500 \mathrm{rpm}$. Afterwards, the resulting TEOS/ETUS sol was diluted with ethanol and deposited onto the membranes.

Before functionalization, the tubular membrane supports were activated as described in [19]. They were boiled in $0.1 \mathrm{~N}$ $\mathrm{HCl}$ for $5 \mathrm{~h}$, washed with water (about $2 \mathrm{~L}$ ) until neutral $\mathrm{pH}$ values, and dried in a muffle furnace at $320^{\circ} \mathrm{C}$ for $6 \mathrm{~h}$. In order to functionalize tubular membrane supports, an excess of sol (about $15 \mathrm{~mL}$ ) was put in contact with the inner surface of the ceramic membrane for the period of $5 \mathrm{~min}$. The excess sol was removed from the sample surface by purging with air.

Thereafter, the functionalized membranes were dried for $2 \mathrm{~h}$ in air (at ambient temperature), for $2 \mathrm{~h}$ at $30^{\circ} \mathrm{C}$ and $50^{\circ} \mathrm{C}$, and $20 \mathrm{~h}$ at $80^{\circ} \mathrm{C}$. The samples were named as TU (planar) and TUt (tubular). The modification degree (MD), in $\mu \mathrm{g}$ of functionalizing coating per $1 \mathrm{~cm}^{2}$ of the membrane surface, was calculated from the difference between the weights of a membrane sample before and after functionalization.

2.3. Methods. Scanning electron microscopy (SEM) was used to investigate the porous structure of the membranes.
The images were obtained with an electron microscope (JSM 6060 LA, Jeol, Japan) using secondary electrons at an accelerating voltage of $30 \mathrm{kV}$. The surface of the samples was covered with a thin continuous layer of gold by cathodic sputtering in vacuum.

FT-IR spectra were recorded on a Thermo Nicolet Nexus FTIR spectrometer using diffuse reflection mode "SMART Collector" in the $4000-400 \mathrm{~cm}^{-1}$ range, with a resolution of $4 \mathrm{~cm}^{-1}$. The samples were ground with $\mathrm{KBr}$ (Fluka, spectranal) at the ratios of sample/ $\mathrm{KBr}=1 / 20$. The spectra were processed with the software of firm-supplier "OMNIC."

For contact angle measurements, a membrane was mounted on a horizontal stage and a water drop $(10 \mu \mathrm{L})$ was placed on its surface with a micrometer syringe. Then, a camera was used to take photographs of the drop profile. The contact angle was measured almost immediately after drop deposition (within 3-5 sec).

2.4. Membrane Filtration Techniques. The filtration of water and aqueous solutions of heavy metal ions ( $\mathrm{Cu}(\mathrm{II}), \mathrm{Ag}(\mathrm{I})$, and $\mathrm{Cd}(\mathrm{II}))$ through the planar membranes was carried out using an Amicon stirred ultrafiltration cell (Millipore Corporation, USA) in the dead-end mode (Figure 1(a)). To analyze the transport properties of tubular membranes, experimental filtration unit with recirculation mode was used (Figure 1(b)). The membrane flux, $J_{v}\left(\mathrm{~L} / \mathrm{m}^{2} \mathrm{~h}\right)$, was calculated by measuring the time needed to collect some volume of the permeate:

$$
J_{v}=\frac{V}{A \cdot t}
$$

where $V$ is the volume of the permeate (L), $A$ is the effective membrane area $\left(\mathrm{m}^{2}\right)$, and $t$ is the time taken to collect the permeate $(h)$.

Working aqueous heavy metal ion solutions were prepared from the batches of the corresponding nitrate salts of these metals: $\mathrm{Cu}\left(\mathrm{NO}_{3}\right)_{2} \cdot 3 \mathrm{H}_{2} \mathrm{O}$ solution ( $\left.\mathrm{pH} \sim 5.8\right), \mathrm{AgNO}_{3}$ solution ( $\mathrm{pH} \sim 2$ ), and $\mathrm{Cd}\left(\mathrm{NO}_{3}\right)_{2} \cdot 4 \mathrm{H}_{2} \mathrm{O}$ solution ( $\mathrm{pH} \sim 5.7$ ). The samples of the permeate and concentrate were tested for the content of $\mathrm{Cu}(\mathrm{II}), \mathrm{Ag}(\mathrm{I})$, and $\mathrm{Cd}(\mathrm{II})$ ions.

Membrane regeneration for copper(II) ion desorption was carried out in the filtration unit in the dynamic mode 


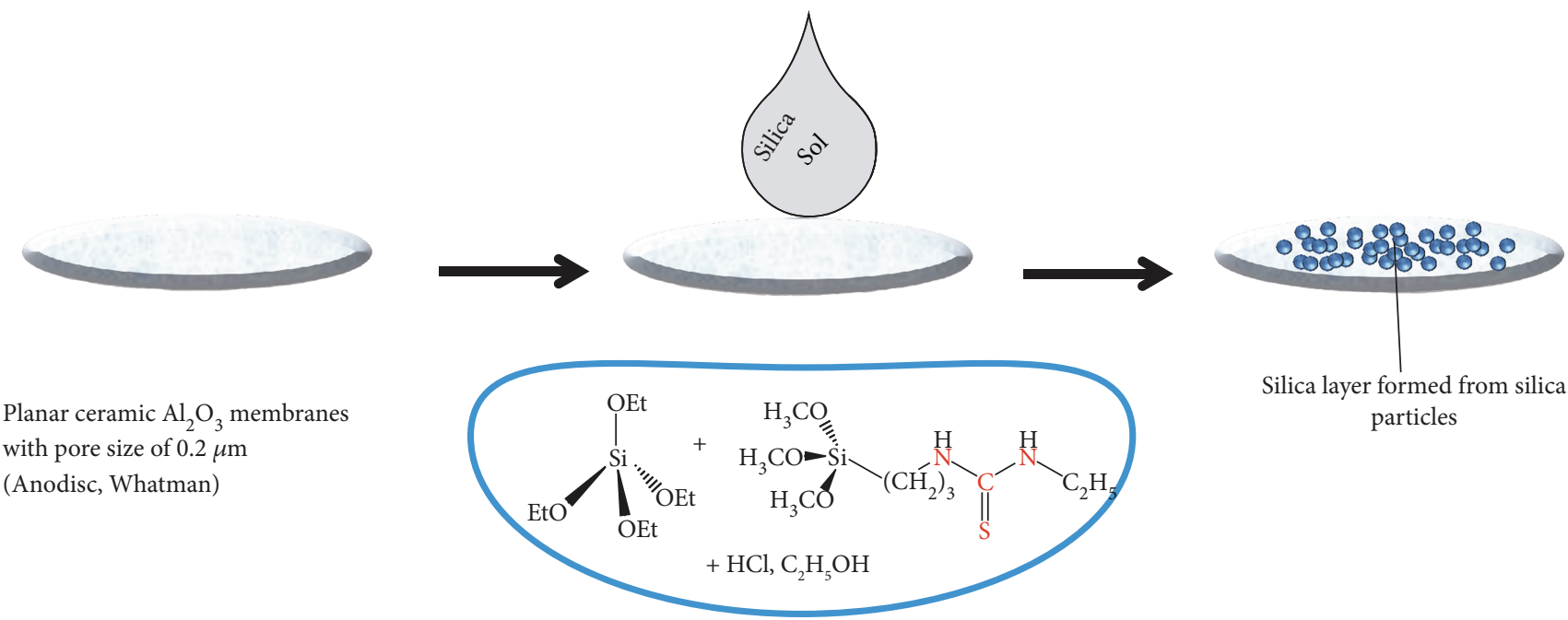

FIGURE 2: Scheme of the reaction of hydrolytic polycondensation of alkoxysilanes.

TABLE 1: Functionalizing membrane supports with thiourea groups.

\begin{tabular}{lccccc}
\hline Sample & Sol/EtOH ratio & Volume of deposited sol $(\mathrm{mL})$ & $\Delta \mathrm{m}(\mathrm{g})$ & $\mathrm{MD}\left(\mu \mathrm{g} / \mathrm{cm}^{2}\right)$ & Thiourea groups content (theor.) $(\mathrm{mmol} / \mathrm{g})$ \\
\hline TU1 & $1 / 4$ & 0.025 & 0.0014 & 335 & 2.65 \\
TU2 & $1 / 8$ & 0.025 & 0.0017 & 410 & 2.65 \\
TU3* & $1 / 8$ & 0.025 & 0.0006 & 145 & 2.65 \\
TU4 & $1 / 8$ & 0.025 & 0.0099 & 2385 & 2.65 \\
TU5 & $1 / 8$ & 0.010 & 0.0013 & 315 & 2.65 \\
TU6 & $1 / 8$ & 0.025 & 0.0022 & 530 & 2.65 \\
TUt & $1 / 2$ & 15 & 0.4529 & 8876 & 2.65 \\
\hline
\end{tabular}

${ }^{*}$ Millipore Swinnex filter holder was used for sol deposition.

by pumping $0.1 \mathrm{~N} \mathrm{HCl}$ solution through the membranes for $30 \mathrm{~min}$, followed by washing with distilled water (still in the filtration unit) till neutral $\mathrm{pH}$ values [20]. After that, the regenerated membranes were dried in an oven at $50^{\circ} \mathrm{C}$ and used for the next adsorption cycle.

Heavy metal ion concentrations in the probes were determined by atomic absorption spectrophotometer C-115-M1 in depleted (oxidative) flame (acetylene/air mixture) using the resonance signals at $328.1 \mathrm{~nm}(\mathrm{Ag}), 324.7 \mathrm{~nm}(\mathrm{Cu})$, and $228.3 \mathrm{~nm}(\mathrm{Cd})$. The source of resonance radiation was a spectral lamp LS-2 with a detection limit of $0.01 \mu \mathrm{g} / \mathrm{cm}^{3}$.

The retention $(R)$ of metal ions by the membranes was calculated as

$$
R=\left(1-\frac{C_{p}}{C_{f}}\right) * 100 \%
$$

where $C_{p}$ and $C_{f}$ are the concentrations of heavy metal ions in the permeate and in the feed solutions, respectively.

\section{Results and Discussion}

Since porous materials with thiourea groups in the surface layer are proved to be perspective for the sorption of heavy metal ions from aqueous solutions, we made an attempt of introduction these groups in the structure of the functionalizing layer of planar ceramic membranes. However, the procedure for the surface layer deposition was similar to the functionalization of membranes with mercapto groups, as described in [21] for planar ceramic membranes and in $[19,22]$ for tubular ones. We used the reaction of hydrolytic copolycondensation of TEOS (as a structure-forming agent) and ETUS (as a source of functional thiourea groups) to form polysiloxane active membrane layers. Preliminary acidic hydrolysis was used for both silanes, as was described earlier in the text, in order to avoid nonhomogenous gelation. The scheme of the reaction is presented in Figure 2.

Because of sufficient viscosity of the original sol, it was diluted with ethanol to facilitate the formation of a homogeneous polysiloxane layer on the membrane surface (Table 1). Such procedure of sol dilution with ethanol earlier are proved effective for the formation of uniform active layers with SH groups $[19,21]$. However, due to the hydrophobicity of the resulting samples with thiourea groups and their poor permeability to water, optimal for the functionalization of planar supports appeared to be nine times the dilution of the original TEOS/ETUS sol. We also used a syringe to blow air through the membrane sample after sol deposition and previous to drying, but it resulted in the decrease of $\mathrm{MD}$ (sample TU3* from Table 1). 


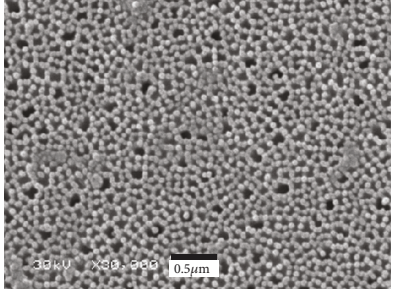

(a)

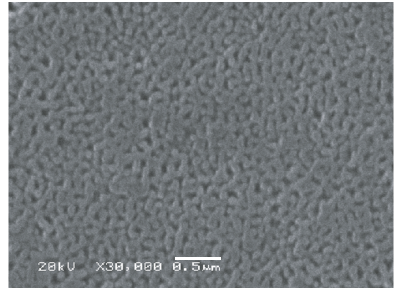

(b)

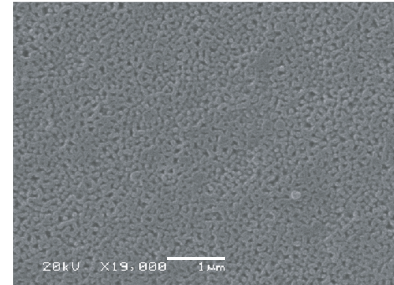

(c)

FIgURE 3: SEM images of the membranes with thiourea functional groups: TU1 (a), TU6 (b), and TU6 regenerated (c).

Figure 3 presents typical SEM images of the active layer of planar membrane supports functionalized with thiourea groups, samples TU1 and TU6. According to it, the functionalizing polysiloxane layer with thiourea groups is composed of nanoparticles. The average size of such particles is about $60-70 \mathrm{~nm}$ for all the samples. These particles are similar to those with 3-mercaptopropyl groups obtained in the same acidic conditions [21]. However, they are smaller than those with 3-aminopropyl groups [23] due to the alkaline properties of 3-aminopropyltriethoxysilane autocatalizing the reaction at an early stage. Therefore, we can conclude that the type of catalyst influences the size of functionalized particles. Also, we can add that the morphology of the membrane does not change during the two cycles of adsorption-desorption (Figure 3(c)) and such modification technique is effective to produce stable membranes for water remediation.

The method of FTIR spectroscopy was used to verify the functionalization, namely, the formation of polysiloxane network, and the incorporation of thiourea groups. For this reason, there were recorded FTIR spectra of thioureafunctionalized silica particles (Figure 4, spectrum 1) and membranes, illustrations of which are plotted in Figure 4. The positions of absorption bands are similar in these three spectra, except for a low-frequency region containing an intensive broad absorption band from an $\mathrm{Al}-\mathrm{O}-\mathrm{Al}$ network of the membrane support. It accords with the composition of functionalized membrane samples witnessed by SEM, namely, consisting of alumina membrane support and active layer formed by functionalized silica particles. FTIR spectroscopy data confirm the presence of thiourea-containing $\mathrm{Si}\left(\mathrm{CH}_{2}\right)_{3} \mathrm{NHC}(\mathrm{S}) \mathrm{NHC}_{2} \mathrm{H}_{5}$ groups in the surface layer of the functionalized membranes. Thiourea ligands are characterized by thione-thiol tautomerism. They have two tautomeric forms: thione $(>\mathrm{C}=\mathrm{S})$ and thiol $(\geq \mathrm{C}$-SH). In our research [17], we showed that during the interaction with silver or mercury ions, the thion form is transformed into thiol, which is evidenced by the decrease in the $\mathrm{pH}$ value of the adsorption solution and FTIR spectra. Thus, the FTIR spectra of the samples have a narrow absorption band of medium intensity at $1549 \mathrm{~cm}^{-1}$, which refers to $v_{\mathrm{as}}(\mathrm{NCN})$ stretches of thiourea fragment $-\mathrm{NH}-\mathrm{C}(\mathrm{S})-\mathrm{NH}-$ and the absorption bands at $1500 \mathrm{~cm}^{-1}$ which can be attributed to the $v(\mathrm{C}=\mathrm{S})$ of the thione form [24]. After 2 cycles of adsorption-desorption, we can observe the appearance of the adsorption band at $1637 \mathrm{~cm}^{-1}$, corresponding $v(\mathrm{~N}=\mathrm{CS})$ of the azomethine group in the thiol form of the thiourea group and this fact confirms our conclusion that during adsorption, the thione form of

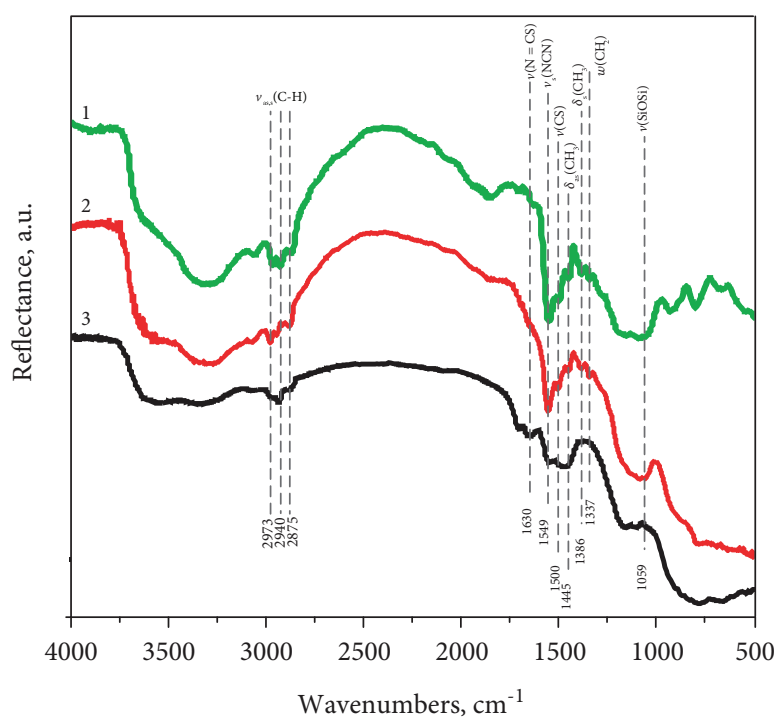

FIgURE 4: FTIR spectra of polysiloxane spheres with thiourea groups (1), membrane functionalized with thiourea groups TU6 (2), and regenerated membrane TU6 after two cycles of $\mathrm{Cu}(\mathrm{II})$ ion adsorption-desorption (3).

thiourea grouping transforms to thiol one [25]. It should be mentioned that in the infrared spectrum of the initial membrane, there are no bands in this spectral region. Thus, the emerging complexes may have the following composition: $\left[(\mathrm{HN})_{2}>\mathrm{C}(-\mathrm{S}-\mathrm{Ag})\right], \quad\left[(\mathrm{HN})_{2}>\mathrm{C}(-\mathrm{S}-\mathrm{Cd}-\mathrm{S}-) \mathrm{C}<(\mathrm{NH})_{2}\right]$, and $\left[(\mathrm{HN})_{2}>\mathrm{C}(-\mathrm{S}-\mathrm{Cu}-\mathrm{S}-) \mathrm{C}<(\mathrm{NH})_{2}\right]$. There are several absorption bands in the region of $2875-2973 \mathrm{~cm}^{-1}$, which can be attributed to the valence vibrations of $\mathrm{C}-\mathrm{H}$ bonds from the methyl and methylene fragments. Also, there is a group of low-intensity bands in the region of $1337-1445 \mathrm{~cm}^{-1}$ related to the bending vibrations of the latter. This indicates the presence of propyl and ethyl chains in the surface layer of functionalized membranes.

Finally, it should be mentioned that the IR spectra of functionalized membranes contain the most intense absorption band in the range of $1059-1200 \mathrm{~cm}^{-1}$ with a high-frequency shoulder. Its presence is associated with the formation of a three-dimensional polysiloxane network [26]. There are wide bands at $\sim 3300 \mathrm{~cm}^{-1}$ and $\sim 3700 \mathrm{~cm}^{-1}$ assigned to $v(\mathrm{NH})$ of thiourea fragment and $v(\mathrm{OH})$ stretches of sorbed water in all DRIFT spectra $[12,17]$. The overlapping of these bands occurs because all the samples contain the water on the surface. 


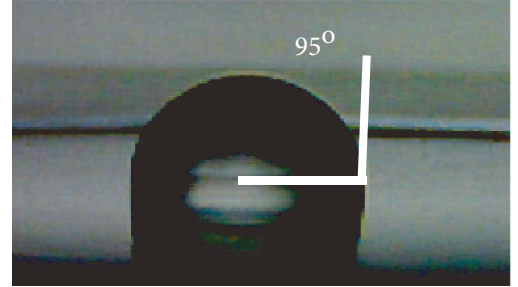

(a)

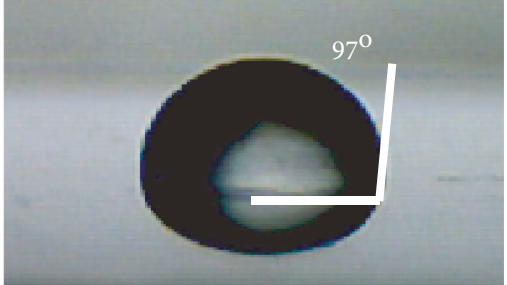

(b)

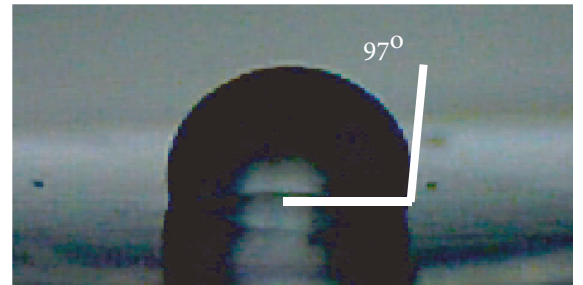

(c)

FIgURE 5: Contact angle measurements for TU1 (a), TU6 (b), and TU6 regenerated (c).

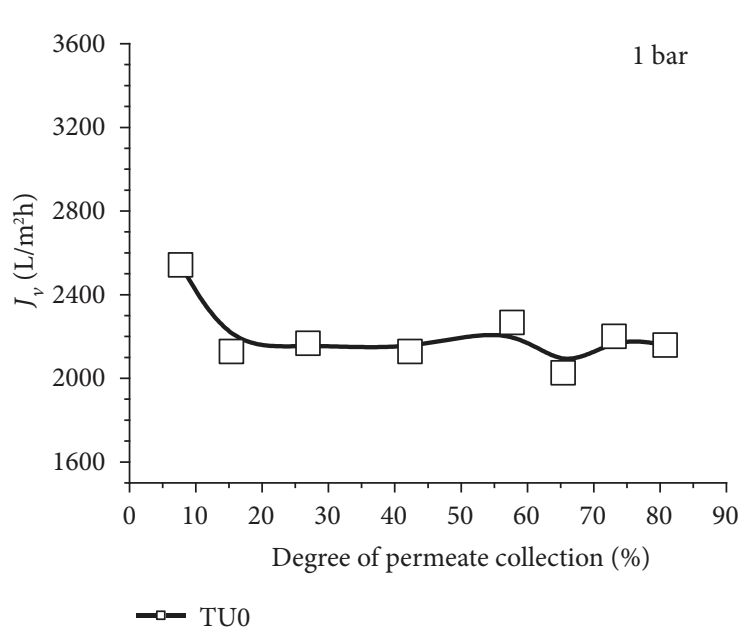

(a)

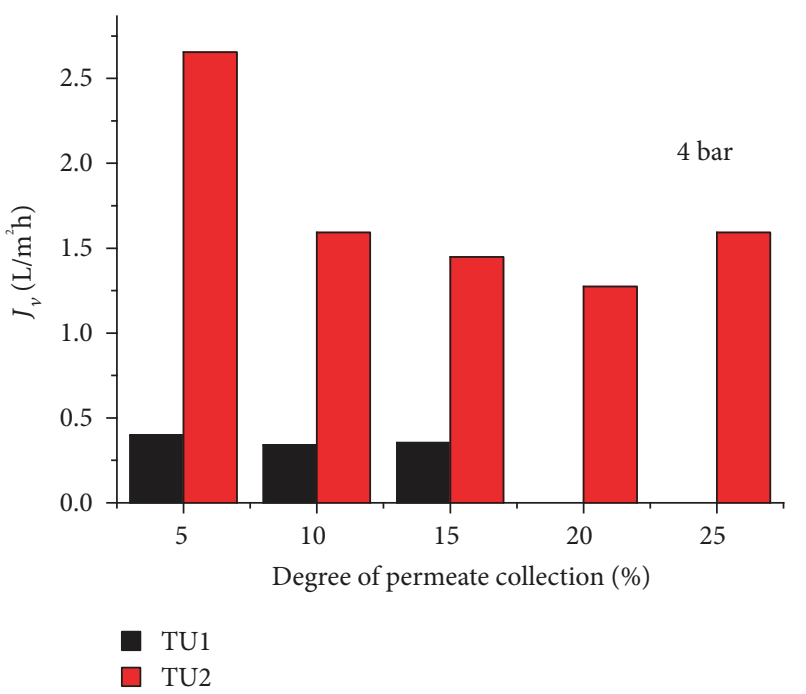

(b)

Figure 6: Water flux through planar membranes, initial (a) and functionalized with thiourea groups (b).

To evaluate the changes in surface hydrophilicity, we conducted the measurement of water contact angles of the membrane supports after functionalization. The water contact angle of the initial membrane support was measured and described earlier [23] and is about $8^{\circ}$, indicating strong hydrophilicity of the sample. However, all the samples with thiourea groups appear to be hydrophobic, independent from the ratio of the sol dilution used for functionalization and MD, as it can be seen in Figure 5 for TU1 and TU6 samples. It also should be mentioned that the contact angle does not change essentially within $2 \mathrm{~min}$ and after copper(II) ion adsorption-desorption (Figure 5(c)). Hydrophobicity of membranes explains the low water flux through such functionalized membranes (Figure 6(b)) compared to $2200 \mathrm{~L} / \mathrm{m}^{2} \mathrm{~h}$ through the original membrane, as can be seen in Figure 6(a).

It appears that the flux through the membranes functionalized with sol nine times diluted with ethanol (TU2) is higher than that through the membrane functionalized with sol five times diluted with ethanol (TU1) (see Figure 6(b)). Such phenomenon may be explained by the formation of a more uniform surface layer in the case of more diluted sol (TU2), as it was observed for thiol-functionalized membranes in [19]. Therefore, nine times sol dilution was used in the further experiments.
To evaluate the performance of functionalized membranes in retention of heavy metal ions, we conducted the experiments with the filtration of model solutions of $\mathrm{Ag}(\mathrm{I})$, $\mathrm{Cd}(\mathrm{II})$, and $\mathrm{Cu}(\mathrm{II})$ nitrate salts (Figure 7). The retention of $\mathrm{Ag}(\mathrm{I})$ and $\mathrm{Cd}(\mathrm{II})$ ions decreases during filtration, with confirms that retention is due to the interaction of ions with the surface functional groups.

However, for the $\mathrm{Cu}(\mathrm{II})$ ions, there is observed increasing retention during the filtration which suggests the involvement of size-exclusion membrane mechanism. An attempt was made to reuse functionalized membranes with thiourea groups in the second cycle after the regeneration procedure. The regeneration was carried out with $0.1 \% \mathrm{HCl}$ acid. Interestingly, that the membranes with thiourea groups showed improved retention of copper(II) ions in the second cycle, comparing with the first (see Figure 8). There can be two possible explanations of increased retention of copper(II) ions in the second cycle. The pressure under which the filtration was performed may cause the compression of the active layer, resulting in lower water permeability and higher metal ion retention. It also can be the influence of hydrochloric acid used for the regeneration, causing the hydrolysis of residual ethoxy groups to silanol. This study was done only for copper(II) ions and may be the subject of further research, but it is known that thiourea groups have an affinity to $\mathrm{Ag}, \mathrm{Cd}$, 


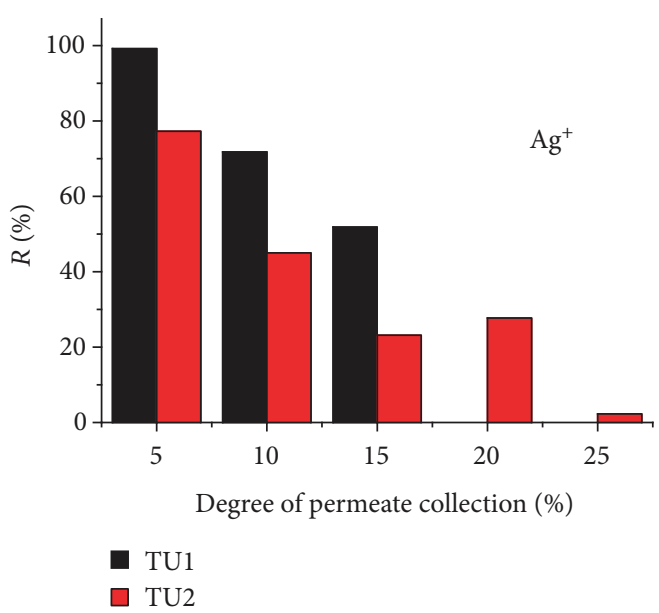

(a)

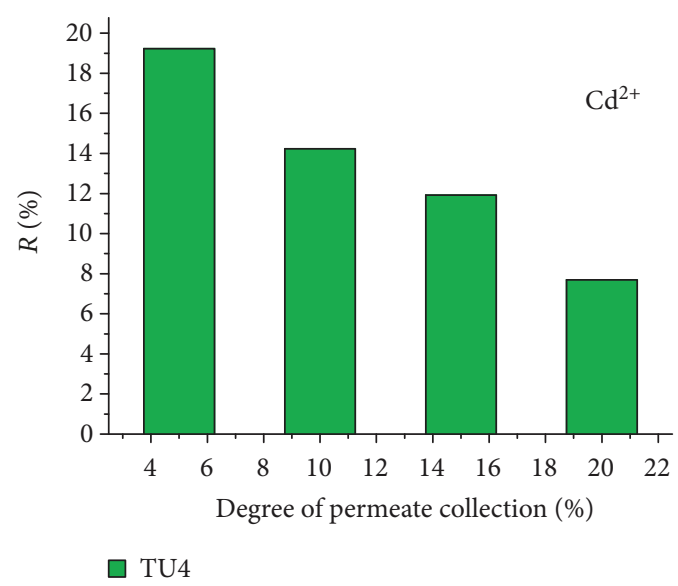

(b)

Figure 7: Silver(I) (a) and cadmium(II) (b) ions retention by membranes with thiourea groups $\left(\mathrm{C}_{\mathrm{Ag}^{+}}=22 \mathrm{mg} / \mathrm{L}, \mathrm{C}_{\mathrm{Cd}^{2+}}=260 \mathrm{mg} / \mathrm{L}, p=4 \mathrm{bar}\right)$.

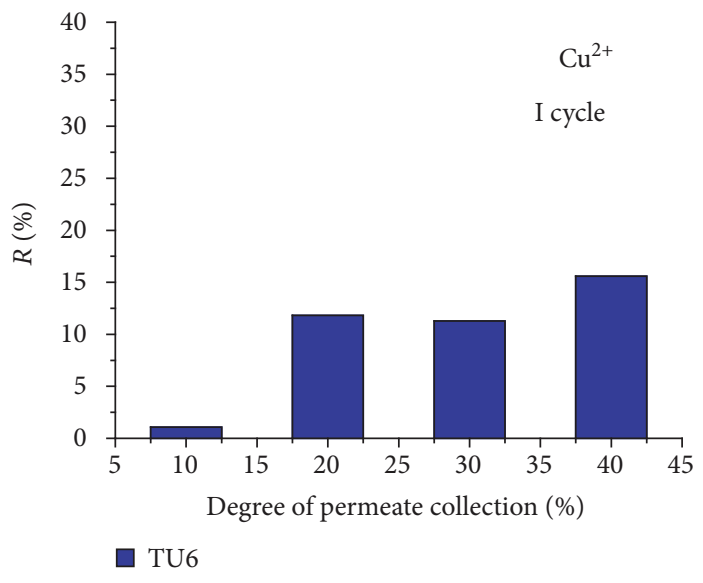

(a)

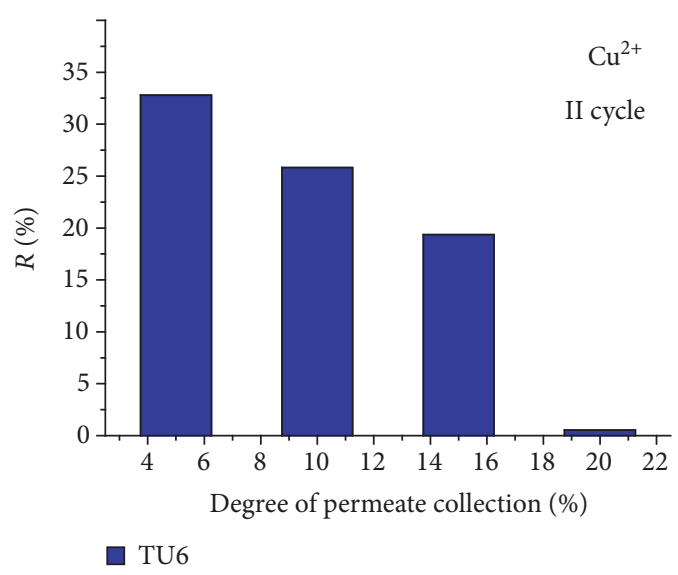

(b)

Figure 8: Copper(II) ions retention by membranes with thiourea groups during first cycle of filtration (a) and second cycle (b) $\left(\mathrm{C}_{\mathrm{Cu}^{2+}}=18.6 \mathrm{mg} / \mathrm{L}, p=4\right.$ bar $)$.

and $\mathrm{Pb}$ metal ions, so they are expected to be adsorbed. As for Ag ions, in our previous article [17], we carried out adsorption and desorption of silver ions by similar functional groups, and one should expect the same mechanism for the membranes.

When analyzing the performance of tubular ceramic membranes in the filtration of water, it was witnessed that water flux decreases strongly after functionalization with polysiloxane layers containing thiourea groups (see Figure 9). Moreover, the water flow through TUt membranes does not vary with pressure and decreases during filtration from about 300 to about $150 \mathrm{~L} / \mathrm{m}^{2} \mathrm{~h}$ (Figure 9(b)). Such behavior may be connected with high hydrophobicity of the samples.

Similar to planar membranes, there were conducted experiments on heavy metal ion retention by tubular alumina membranes with thiourea functions, using copper(II) nitrate model solutions (see Figure 10). The regeneration was conducted with $0.1 \mathrm{~N} \mathrm{HCl}$. The retention of copper ions decreases with time during filtration both in the first and in the second cycles, which suggests that the retention is mainly due to the ion interaction with the surface thiourea groups.

Moreover, the retention of copper(II) ions appeared to be the same before and after regeneration. However, a substantial decrease in water flow through the membrane after the regeneration was observed. This, similar to the functionalized planar membranes, may suggest some changes in the properties of the functionalizing layer during the regeneration procedure.

\section{Conclusions}

The Sol-gel method based on the reaction of hydrolytic polycondensation of alkoxysilanes was used for creating selective layers with amino and thiourea groups on the surfaces of planar and tubular ceramic membranes. It was shown that such 


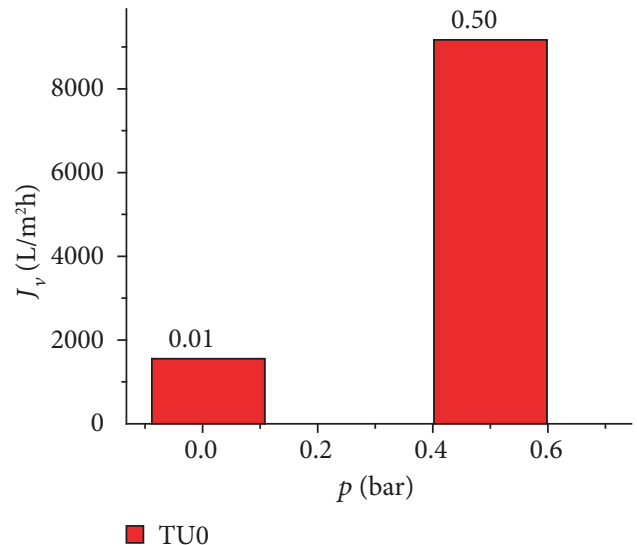

(a)

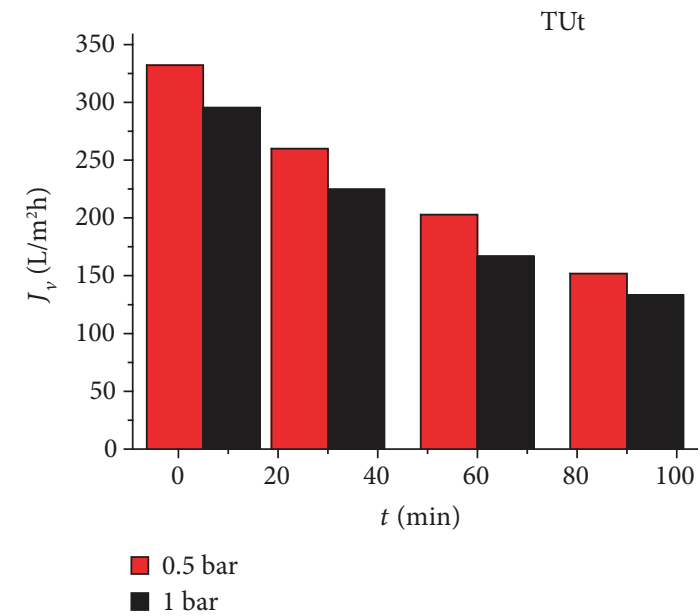

(b)

FIGURE 9: Water flux through tubular membranes, initial (a) and functionalized with thiourea groups (b).

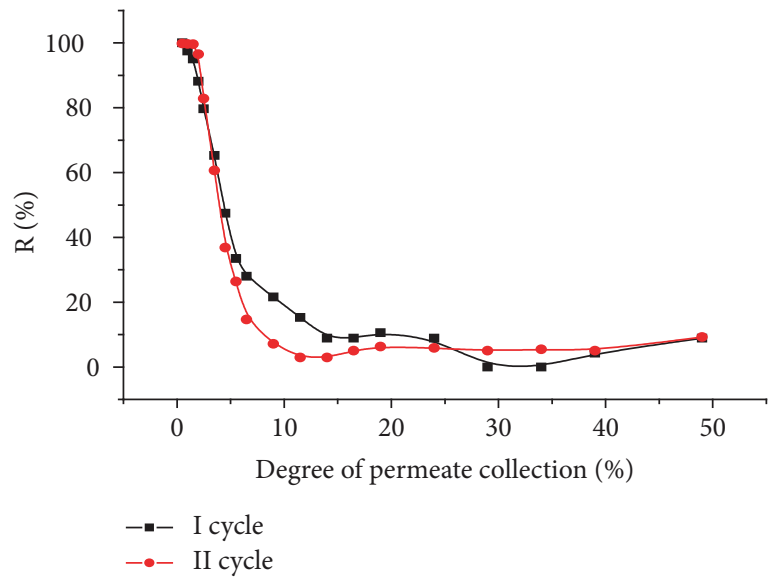

(a)

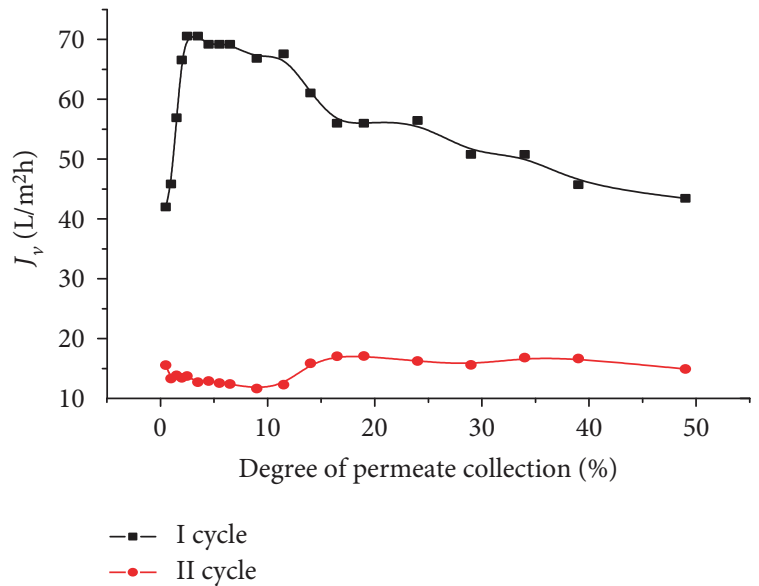

(b)

FIGURE 10: Retention (a) and water flux (b) for tubular membrane with thiourea groups (TUt) in the filtration of $\left.\mathrm{Cu}_{(\mathrm{NO}}\right)_{2}, \mathrm{C}_{\mathrm{Cu}^{2+}}=22 \mathrm{mg} / \mathrm{L}$, $p=1$ bar, and regeneration: $0.1 \mathrm{~N} \mathrm{HCl}$.

approach allows influencing the degree of hydrophobicity of the created surface layer. Additionally, it allows controlling the porous structure of the surface layer at the stage of formation and ripening of silica sol and its transition to gel, by varying the ratio of reactants, the nature of the solvent, and the drying mode.

The identification of functional coatings on the surface of planar ceramic membranes was carried out by means of IR spectroscopy, while their morphology was analyzed with SEM. It is necessary to use diluted sols for the formation of monolayer-like coating and better interaction of the particles with the surface of the support. It will ensure better fixation of the active layer and contribute to the membrane exploitation in several cycles. It was shown that the deposited layers adsorb heavy metal ions, such as copper(II), silver(I), and cadmium(II). There possibility of membrane regeneration with hydrochloric acid and reuse in several cycles of
copper(II) ion sorption/desorption was also shown. An important feature of the proposed functionalization technique is the possibility of introducing other functional groups in the surface of ceramic membranes, i.e., depending on the practical task; there is the possibility of preparing sols with different silanes.

\section{Data Availability}

The SEM, FTIR, and metal ion solution filtration data used to support the findings of this study are included within the article.

\section{Conflicts of Interest}

The authors declare no conflict of interest. 


\section{Acknowledgments}

The research was funded by NATO Science for Peace and Security Program SPS.NUKR.SFP 984398 (2012-2017).

\section{References}

[1] H. Strathmann, "Membranes and membrane separation processes, 1. Principles," in Book Ullman's Encyclopedia of Industrial Chemistry, vol. 22, pp. 413-456, Wiley-VCH Verlag $\mathrm{GmbH} \&$ Co. KGaA, Weinheim, 2012.

[2] A. K. Singh, A. K. Jain, and S. Mehtab, "Ytterbium-selective polymeric membrane electrode based on substituted urea and thiourea as a suitable carrier," Analytica Chimica Acta, vol. 597, no. 2, pp. 322-330, 2007.

[3] M. G. Motlagh, M. A. Taher, and A. Ahmadi, "PVC membrane and coated graphite potentiometric sensors based on 1-phenyl-3-pyridin-2-yl-thiourea for selective determination of iron(III)," Electrochimica Acta, vol. 55, no. 22, pp. 67246730, 2010.

[4] D. Wilson, M. de los Angeles Arada, S. Alegret, and M. del Valle, "Lead(II) ion selective electrodes with PVC membranes based on two bis-thioureas as ionophores: 1,3-bis $\left(\mathrm{N}^{\prime}\right.$-benzoylthioureido)benzene and 1,3-bis( $\mathrm{N}^{\prime}$-furoylthioureido)benzene," Journal of Hazardous Materials, vol. 181, no. 1-3, pp. 140-146, 2010.

[5] H. A. Zamani, B. Feizyzadeh, F. Faridbod, and M. R. Ganjali, "Application of 1-ethyl-3-(2,5-dihydro-4-(3,5-dimethyl-1Hpyrazol-4-yl)-5-oxo-1H-pyrazol-3-yl)thiourea as sensing material for construction of $\mathrm{Tm}^{3+}$-PVC membrane sensor," Materials Science and Engineering: C, vol. 31, no. 7, pp. 1379-1382, 2011.

[6] F. Z. el Aamrani, J. García-Raurich, A. Sastre, L. Beyer, and A. Florido, "PVC membranes based on silver(I)-thiourea complexes," Analytica Chimica Acta, vol. 402, no. 1-2, pp. 129-135, 1999.

[7] N. G. Lukyanenko, N. Y. Titova, N. L. Nesterenko, T. I. Kirichenko, and S. Scherbakov, "Cation slectivity of poly (vinyl chloride) membranes based on cryptands with thiourea fragments," Analytica Chimica Acta, vol. 263, no. 1-2, pp. 169-173, 1992.

[8] M. Ghanei-Motlagh, M. Fayazi, and M. A. Taher, "On the potentiometric response of mercury(II) membrane sensors based on symmetrical thiourea derivatives - experimental and theoretical approaches," Sensors and Actuators B, vol. 199, pp. 133-141, 2014.

[9] D. Ruan, L. Zhang, Y. Mao, M. Zeng, and X. Li, "Microporous membranes prepared from cellulose in $\mathrm{NaOH}$ /thiourea aqueous solution," Journal of Membrane Science, vol. 241, no. 2, pp. 265-274, 2004.

[10] H. Li, X. Wang, L. Cao, X. Zhang, and C. Yang, "Gold-recovery PVDF membrane functionalized with thiosemicarbazide," Chemical Engineering Journal, vol. 280, pp. 399-408, 2015.

[11] X. Wang, J. Xu, L. Li, H. Li, and C. Yang, "Thiourea grafted PVDF affinity membrane with narrow pore size distribution for $\mathrm{Au}$ (III) adsorption: preparation, characterization, performance investigation and modeling," Chemical Engineering Journal, vol. 314, pp. 700-713, 2017.

[12] I. V. Melnyk, O. I. Gona, L. I. Kozhara et al., "Study of $\mathrm{Hg}^{2+}$ sorption from water solutions by mesoporous silica with thiourea functional groups," in Sol-Gel Methods for Materials Processing. NATO Science for Peace and Security Series C:
Environmental Security, P. Innocenzi, Y. L. Zub, and V. G. Kessler, Eds., pp. 375-381, Springer, Dordrecht, 2008.

[13] I. V. Mel'nik, N. V. Stolyarchuk, Y. L. Zub, and A. Dabrowski, "Polysiloxane xerogels containing arch-fixed urea groups," Russian Journal of Applied Chemistry, vol. 79, no. 6, pp. 981986, 2006.

[14] O. I. Gona, Y. L. Zub, N. A. Yaroshenko, and J. Goworek, "Influence of synthesis conditions on the structure of mesoporous silicas containing thiourea functional group," Polish Journal of Chemistry, vol. 82, pp. 299-306, 2008.

[15] G. I. Nazarchuk, I. V. Melnyk, Y. L. Zub, O. I. Makridina, and A. I. Vezentsev, "Mesoporous silica containing $\equiv \mathrm{Si}\left(\mathrm{CH}_{2}\right)_{3} \mathrm{NHC}(\mathrm{S}) \mathrm{NHC}_{2} \mathrm{H}_{5}$ functional groups in the surface layer," Journal of Colloid and Interface Science, vol. 389, no. 1, pp. 115-120, 2013.

[16] Y. L. Zub, I. V. Melnyk, O. A. Dudarko et al., "Nanoporous sorbents with complexing surface layer: synthesis, structure, application," in Nanoscale Systems and Nanomaterials: Research in Ukraine, Chapter: Nanochemistry, A. G. Naumovets, Ed., pp. 680-685, Akademperiodika, Kiev, 2014.

[17] I. V. Melnyk, G. I. Nazarchuk, M. Vaclavikova, and Y. L. Zub, "IR spectroscopy study of SBA-15 silicas functionalized with the ethylthiocarbamidepropyl groups and their interactions with $\mathrm{Ag}(\mathrm{I})$ and $\mathrm{Hg}(\mathrm{II})$ ions," Applied Nanoscience, 2018.

[18] I. V. Mel'nik, O. V. Lyashenko, Y. L. Zub, A. A. Chuiko, D. Cauzzi, and G. Predieri, "Synthesis of alkoxysilanes as starting substances for preparation of new materials by the sol-gel procedure. Silanes with urea functional group," Russian Journal of General Chemistry, vol. 74, no. 11, pp. 1658-1664, 2004.

[19] V. V. Tomina, I. V. Mel'nik, R. P. Pogorilyi, V. M. Kochkodan, and Y. L. Zub, "Functionalization of the surface of ceramic membranes with 3-mercaptopropyl groups using the sol-gel method," Protection of Metals and Physical Chemistry of Surfaces, vol. 49, no. 4, pp. 386-391, 2013.

[20] G. G. Paradis, R. Kreiter, M. M. A. van Tuel, A. Nijmeijer, and J. F. Vente, "Amino-functionalized microporous hybrid silica membranes," Journal of Materials Chemistry, vol. 22, no. 15, pp. 7258-7264, 2012.

[21] V. V. Tomina, N. V. Stolyarchuk, I. V. Melnyk, V. M. Kochkodan, and Y. L. Zub, "Sorptive ceramic membranes functionalized with HS-groups," Microporous and Mesoporous Materials, vol. 209, pp. 66-71, 2015.

[22] V. V. Tomina, N. V. Stolyarchuk, I. V. Melnyk et al., "Composite sorbents based on porous ceramic substrate and hybrid amino- and mercapto-silica materials for $\mathrm{Ni}(\mathrm{II})$ and $\mathrm{Pb}(\mathrm{II})$ ions removal," Separation and Purification Technology, vol. 175, pp. 391-398, 2017.

[23] V. V. Tomina, N. V. Stolyarchuk, I. V. Melnyk et al., "Surface functionalization of ceramic membranes with 3-aminopropyl groups using the sol-gel method," Protection of Metals and Physical Chemistry of Surfaces, vol. 52, no. 1, pp. 55-60, 2016.

[24] K. A. Jensen, P. H. Nielsen, L. G. Sillén et al., "Infrared spectra of thioamides and selenoamides," Acta Chemica Scandinavica, vol. 20, no. 3, pp. 597-629, 1966.

[25] G. I. Nazarchuk, I. V. Melnyk, O. S. Papayanina, and Y. L. Zub, "Synthesis of spherical particles of silica with thiourea groups in their surface layer," Nanosystems, Nanomaterials, Nanotechnologies, vol. 11, no. 4, pp. 769-780, 2013.

[26] L. P. Finn and I. B. Slinyakova, "Structure and thermodestruction of polyorganosiloxane xerogels using IR spectroscopy data," Colloid Journal, vol. 37, no. 4, pp. 723-729, 1975. 


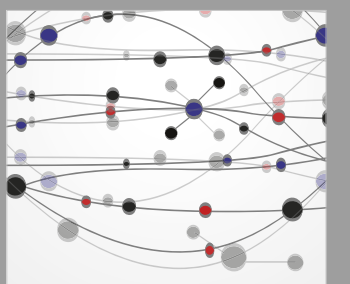

The Scientific World Journal
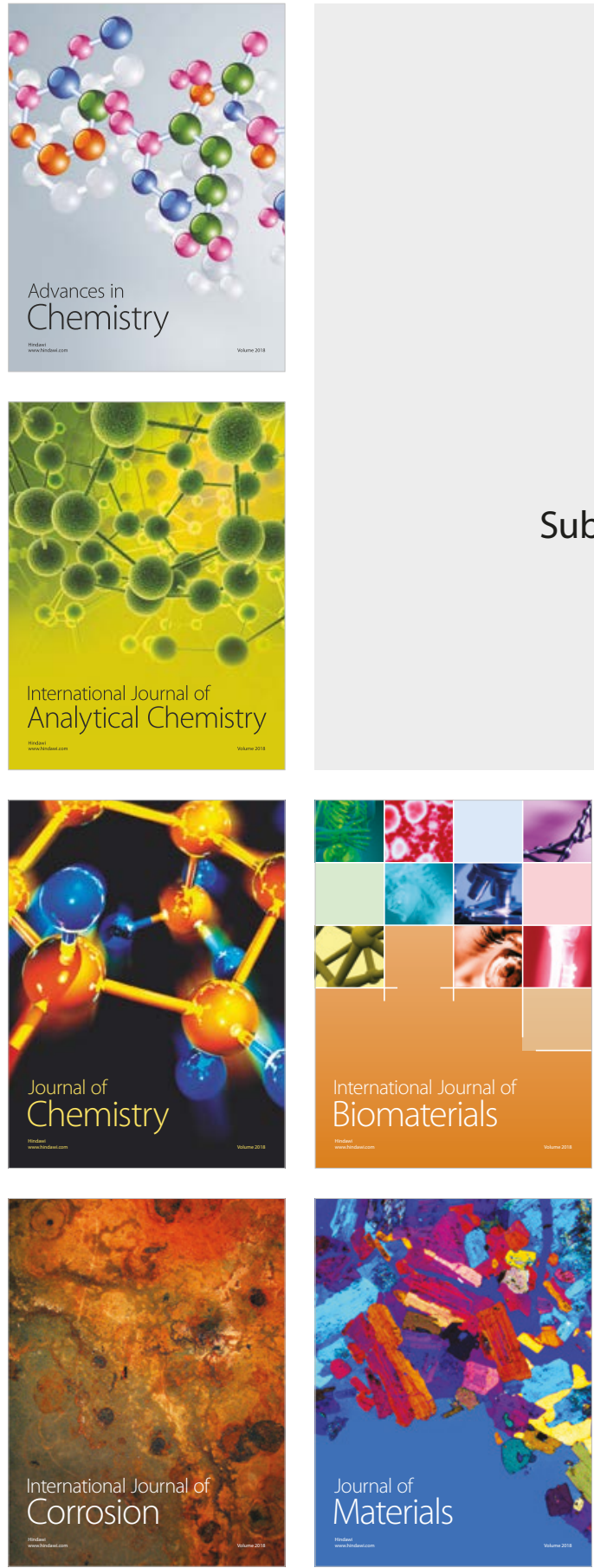

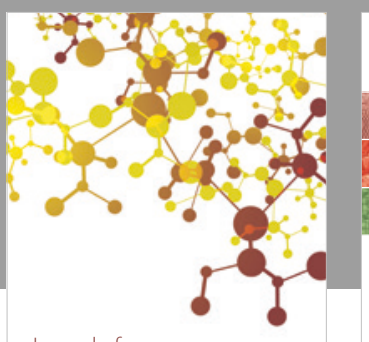

Journal of

Applied Chemistry
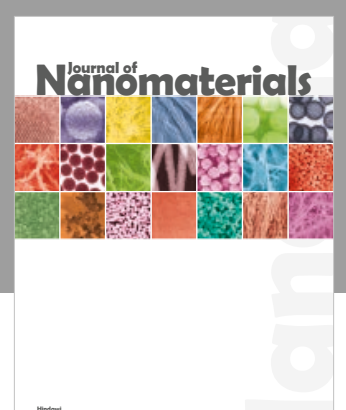

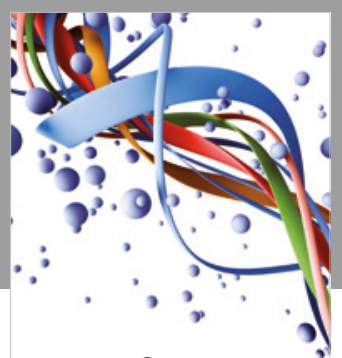

Scientifica

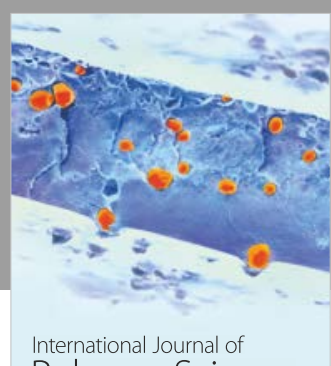

Polymer Science

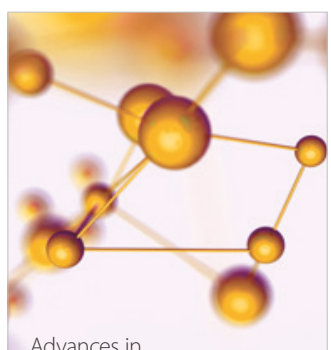

Physical Chemistry
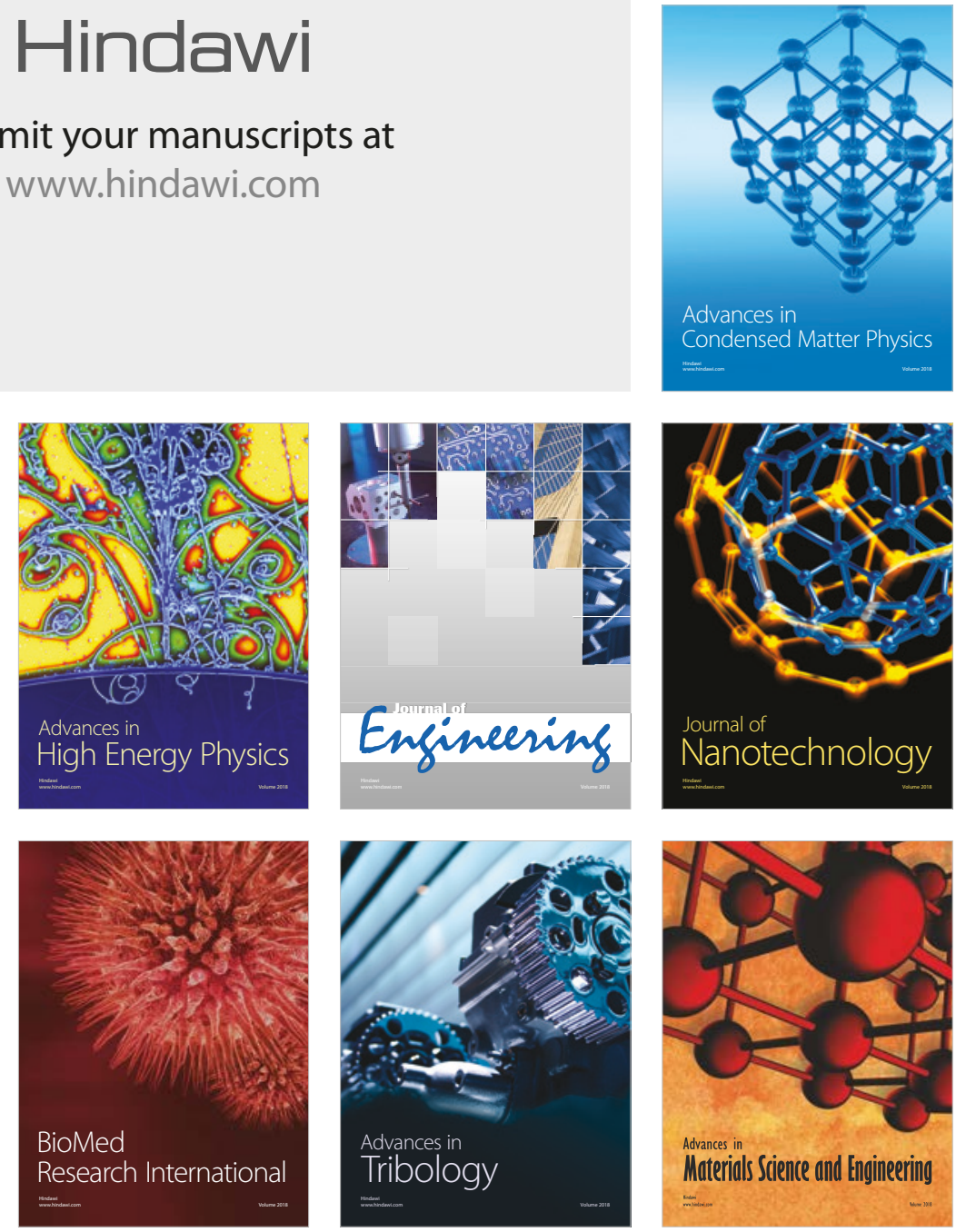